\title{
Inclusion of Acetonitrile in a Macrobicyclic Host Molecule
}

\section{Fritz Vögtle, * a Ralf Berscheid a and Wolfgang Schnickb}

a Institut für Organische Chemie und Biochemie der Universität Bonn, Gerhard-Domagk-Strasse 1, D-5300 Bonn 1, Germany

b Institut für Anorganische Chemie der Universität Bonn, Gerhard-Domagk-Strasse 1, D-5300 Bonn 1, Germany

The first inclusion complex of acetonitrile in a molecular cavity is described; $X$-ray structure and IR spectra show that the $\pi$-donor host 4 encloses acetonitrile as a $\pi$-acceptor selectively inside its molecular cavity, whereas empty intermolecular cavities are not occupied by acetonitrile.

We describe for the first time the inclusion of acetonitrile in a molecular cavity. In earlier reported molecular complexes acetonitrile is oriented above and below a crown ether ring or bound by weak forces in intercalates. ${ }^{1}$ In contrast our host 4 encloses acetonitrile exclusively inside the molecular cavity (Fig. 1). Intermolecular empty space in the crystal lattice is unoccupied.

Tris(4-methoxyphenyl)methanol $\mathbf{1}$ served as starting material for the synthesis (Scheme 1). Unlike the synthesis given in the literature, ${ }^{2}$ it was easily available through Grignard reaction from 4,4'-dimethoxybenzophenone and 4-bromoanisole in $51 \%$ yield (after separation by column chromatography). Deprotection of the methoxy groups was achieved by reaction with sodium ethyl sulphide in refluxing dimethylformamide. ${ }^{3}$ The triphenylmethanol group was simultaneously reduced to the triphenylmethane unit. In this demethylation-reduction one-pot reaction sequence the tris(hydroxyphenyl)methane $\mathbf{2}$ is obtained in $93 \%$ yield. Further conversion was achieved by standard methods with prop-2-ynyl bromide- $\mathrm{K}_{2} \mathrm{CO}_{3}$ in refluxing acetone and produced the tris-propynylic ether 3 in $74 \%$ yield after separation by column chromatography (cyclohexane-diethyl ether, $1: 4)$

The dimerization of $\mathbf{3}$ to $\mathbf{4}$ followed the method of Breslow 4 using $\mathrm{CuCl}-\mathrm{CuCl}_{2}$ in dry pyridine free of oxygen. After separation by column chromatography (cyclohexane-diethyl ether- $\mathrm{CH}_{2} \mathrm{Cl}_{2}$-triethylamine, $20: 20: 1: 1$ ) the macrobicyclic compound 4 was obtained in $35 \%$ yield as a colourless solid which decomposes at $270^{\circ} \mathrm{C} . \dagger$

Recrystallization from acetonitrile yielded the inclusion complex $4 \cdot \mathrm{MeCN}$ as colourless needles, also decomposing at $270{ }^{\circ} \mathrm{C}$. The ${ }^{1} \mathrm{H}$ NMR spectrum of $4 \cdot \mathrm{MeCN}$ measured in

$\uparrow$ Satisfactory analytical and spectroscopic data were obtained for compounds 3 and $\mathbf{4}$. Compound 3 , m.p. $78-79{ }^{\circ} \mathrm{C}$, colourless needles (from ethanol); $R_{\mathrm{f}} 0.53$ [hexane-diethyl ether, $1: 4$, silica gel 60 (Riedel No. 37333)]; ${ }^{1} \mathrm{H}$ NMR ( $90 \mathrm{MHz} ; \mathrm{CD}_{2} \mathrm{Cl}_{2} ; J$ values in $\mathrm{Hz}$ ): $\delta$ $2.48(\mathrm{t}, J 2.5,3 \mathrm{H}, \equiv \mathrm{C}-\mathrm{H}), 4.62\left(\mathrm{~d}, J 2.5,6 \mathrm{H}, \mathrm{OCH}_{2}\right), 5.38(\mathrm{~s}, 1 \mathrm{H}$, $\left.\mathrm{Ar}_{3} \mathrm{CH}\right), 6.84\left(\mathrm{dd}, J_{o} 9.0, J_{m} 2.0,6 \mathrm{H}, \mathrm{HC}-3,5\right)$ and $7.00\left(\mathrm{dd}, J_{o} 9.0, J_{m}\right.$ $2.0,6 \mathrm{H}, \mathrm{HC}-2,6) ;{ }^{13} \mathrm{C} \mathrm{NMR}\left(22.6 \mathrm{MHz}, \mathrm{CDCl}_{3}\right): \delta 54.47(\mathrm{~d}, 1 \mathrm{C}$, $\left.\mathrm{Ar}_{3} \mathrm{CH}\right), 55.90\left(\mathrm{t}, 3 \mathrm{C}, \mathrm{OCH}_{2}\right), 75.51(\mathrm{~d}, 3 \mathrm{C}, \equiv \mathrm{C}-\mathrm{H}), 78.75(\mathrm{~s}, 3 \mathrm{C}$, $\left.\equiv C-\mathrm{CH}_{2}\right), 114.71(\mathrm{~d}, 6 \mathrm{C}, \mathrm{C}-3,5), 130.35(\mathrm{~d}, 6 \mathrm{C}, \mathrm{C}-2,6), 137.53(\mathrm{~s}, 3 \mathrm{C}$, $\mathrm{C}-1)$ and $156.11(\mathrm{~s}, 3 \mathrm{C}, \mathrm{C}-4) ; \mathrm{m} / \mathrm{z} 406.1577\left(\mathrm{C}_{28} \mathrm{H}_{22} \mathrm{O}_{3}\right)(100 \%), 405$ (8), 367 (45), $366(2), 351(36), 328$ (6), 327 (4), 289 (9), 275 (42), 274 (16), $236(16), 235$ (35) and 197 (9); IR (KBr) $v_{\max } / \mathrm{cm}^{-1} 3360 \mathrm{~m}$, $3090 \mathrm{w}, 3050 \mathrm{w}, 3000 \mathrm{w}, 2960 \mathrm{w}, 2915 \mathrm{w}, 2872 \mathrm{w}, 2140 \mathrm{~m}, 1621 \mathrm{~s}, 1595 \mathrm{~m}$, $1520 \mathrm{vs}, 1471 \mathrm{~m}, 1398 \mathrm{~m}, 1375 \mathrm{~m}, 1307 \mathrm{~s}, 1268 \mathrm{vs}, 1193 \mathrm{~s}, 1130 \mathrm{~s}, 1050 \mathrm{vs}$, $938 \mathrm{~m}, 845 \mathrm{~s}, 825 \mathrm{~s}, 785 \mathrm{~m}, 600 \mathrm{~s}$ and $570 \mathrm{~s} ; \mathrm{UV}$ (dioxane) $\lambda_{\max } / \mathrm{nm} 208(\varepsilon$ $32280), 233(21090), 275$ (4890) and 284 (4260).

Compound 4 , colourless solid, decomp. without melting $>270{ }^{\circ} \mathrm{C}$; $R_{\mathrm{f}} 0.46$ (hexane-diethyl ether $1: 4$, silica gel 60 (Riedel No. 37333)]; ${ }^{1} \mathrm{H}$ NMR $\left(90 \mathrm{MHz},\left[{ }^{2} \mathrm{H}_{8}\right]\right.$ dioxane; $J$ values in $\left.\mathrm{Hz}\right): \delta 4.80(\mathrm{~s}, 12 \mathrm{H}$, $\left.\mathrm{OCH}_{2}\right), 5.45\left(\mathrm{~s}, 2 \mathrm{H}, \mathrm{Ar}_{3} \mathrm{CH}\right), 6.91\left(\mathrm{dd}, J_{o} 9.0, J_{m} 2.0,12 \mathrm{H}, H \mathrm{C}-3,5\right)$ and $7.03\left(\mathrm{dd}, J_{o} 9.0, J_{m} 2.0,12 \mathrm{H}, \mathrm{HC}-2,6\right) ;{ }^{13} \mathrm{C}$ NMR $(100 \mathrm{MHz}$, $\left[{ }^{2} \mathrm{H}_{8}\right]$ dioxane $): \delta 54.76\left(\mathrm{~d}, 2 \mathrm{C}, \mathrm{Ar}_{3} \mathrm{CH}\right), 55.86\left(\mathrm{t}, 6 \mathrm{C}, \mathrm{OCH}_{2}\right), 70.41(\mathrm{~s}$, $6 \mathrm{C}, \equiv \mathrm{C}-\mathrm{C} \equiv), 76.58\left(\mathrm{~s}, 6 \mathrm{C}, \equiv \mathrm{C}-\mathrm{CH}_{2}\right), 114.65(\mathrm{~d}, 12 \mathrm{C}, \mathrm{C}-3,5), 131.24$ (d, 12C, C-2,6), 138.31 (s, 6C, C-1) and 156.65 (s, 6C, C-4); FAB-MS $807\left(\mathrm{C}_{56} \mathrm{H}_{38} \mathrm{O}_{6}:[\mathrm{M}+\mathrm{H}]^{*+}\right)$; IR $(\mathrm{KBr}) \mathrm{v}_{\text {max }} / \mathrm{cm}^{-1} 3059 \mathrm{w}, 3031 \mathrm{w}$, $2995 \mathrm{w}, 2915 \mathrm{w}, 2857 \mathrm{w}, 2255 \mathrm{w}, 2185 \mathrm{w}, 2136 \mathrm{w}, 2028 \mathrm{w}, 1609 \mathrm{~s}, 1586 \mathrm{~m}$, $1505 \mathrm{vs}, 1447 \mathrm{~m}, 1359 \mathrm{~m}, 1303 \mathrm{~m}, 1263 \mathrm{~s}, 1215 \mathrm{vs}, 1176 \mathrm{~s}, 1024 \mathrm{~s}, 930 \mathrm{~m}$, $823 \mathrm{~s}, 771 \mathrm{w}$ and $635 \mathrm{w}$; UV (dioxane) $\lambda_{\max } / \mathrm{nm} 207$ (ع 45560), 231 $(24320), 275$ (6970) and 285 (6400).<smiles>COc1ccc(C(O)(c2ccc(OC)cc2)c2ccc(OC)cc2)cc1</smiles>
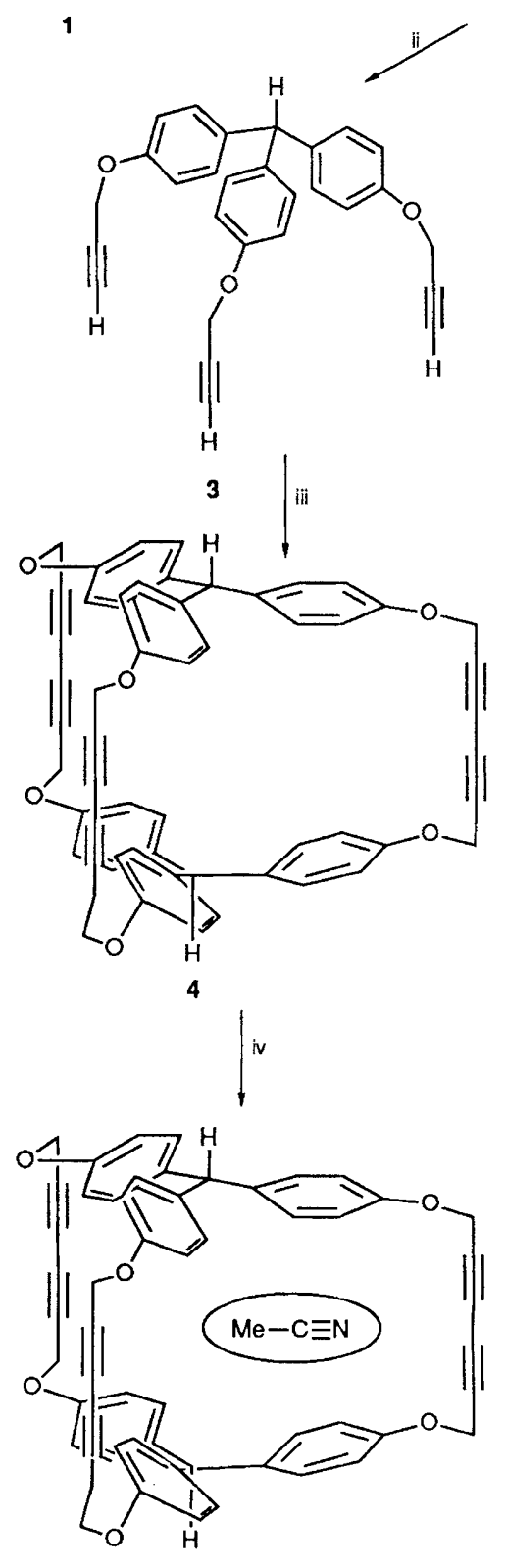

4. MeCN

Scheme 1 Reagents and conditions: i, NaSEt, dimethylformamide (DMF), reflux, 1 day $(93 \%)$; ii, prop-2-ynyl bromide, $\mathrm{K}_{2} \mathrm{CO}_{3}$, acetone, reflux $3 \mathrm{~h}$, chromatography $(74 \%)$; iii, $\mathrm{CuCl}-\mathrm{CuCl}_{2}$, pyridine, room temp., 7 days, high dilution conditions, chromatography $(35 \%)$; iv, recrystallization from acetonitrile 

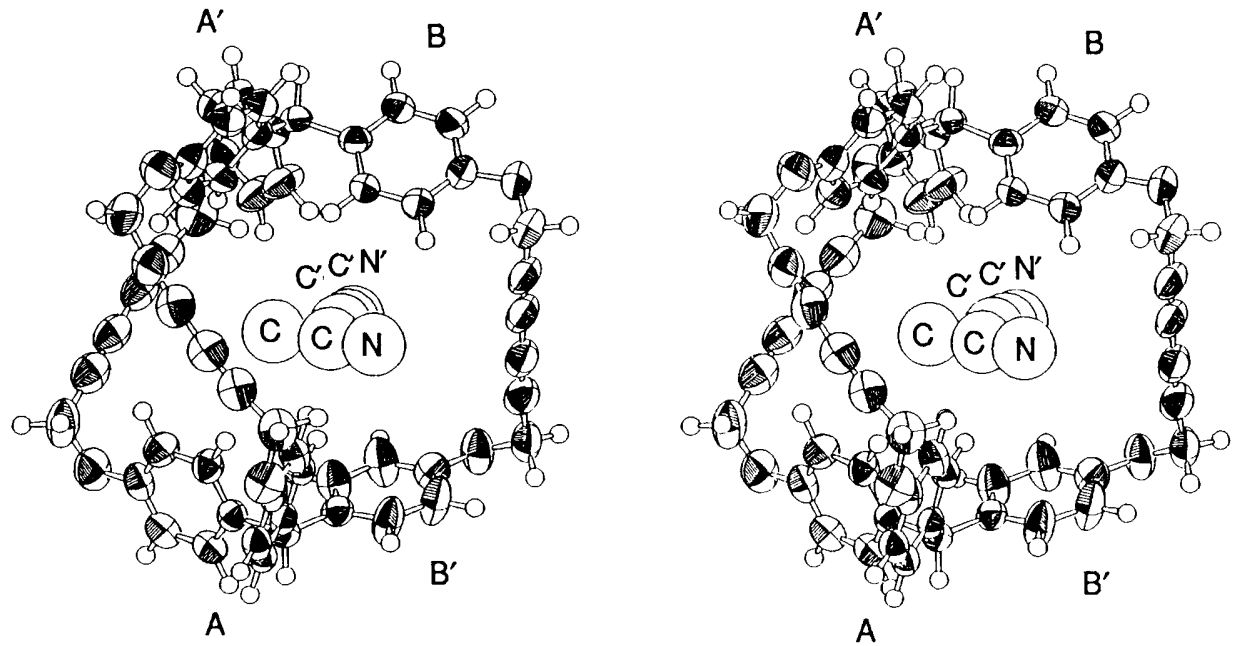

Fig. 1 ORTEP drawing of complex $4 \cdot \mathrm{MeCN}$ (stereoview). The enclosed acetonitrile is found in two split positions in a $1: 1$ ratio.

$\mathrm{CD}_{2} \mathrm{Cl}_{2}$ showed signals due to both the free host 4 and free $\mathrm{MeCN}$ a 1:1 ratio, at the same position as for the separate components. In solution the equilibrium seems to be far on the side of the components. The same result was obtained from the IR spectrum of a solution of $4 \cdot \mathrm{MeCN}$ (measured as a $\mathrm{CH}_{2} \mathrm{Cl}_{2}$ film).

However the IR spectrum of the crystalline complex in a $\mathrm{KBr}$ matrix shows a significant shift of the nitrile band, $\Delta v=$ $35 \mathrm{~cm}^{-1}$, towards smaller wavenumbers $\left(v 2218.5 \mathrm{~cm}^{-1}\right)$ with nearly identical positions of the IR bands of the complexed host $\mathbf{4}$ compared to those of the guest-free host (acetonitrile in $\mathrm{KBr}$ absorbs at $v 2254 \mathrm{~cm}^{-1}$ under similar conditions).

The geometry of the complex $4 \cdot \mathrm{MeCN}$ was established by a single crystal X-ray structural analysis (Figs. 1 and 2 ). $\neq$ The host is twisted along its pseudo-threefold axis. The enclosed acetonitrile guest is found at the equatorial level perpendicular to this axis of the host $\mathbf{4}$ in two split positions with an occupancy factor of 0.5 . The methyl group is located in the centre of the cavity. No acetonitrile is found in the intermolecular cavities. The maximum residual electron density is 0.28 e $\AA^{-3}$.

As Fig. 2 shows, two of the three bridges of the host $\mathbf{4}$ are geometrically similar. The third diyne bridge shows a remarkable feature induced by the acetonitrile inclusion. The X-ray analysis reveals a reduced distance between the two benzene rings ( $\mathrm{B}$ and $\mathrm{B}^{\prime}$ in Fig. 1, $861 \mathrm{pm}$ ) as compared to the distances between the benzene rings of the other bridges ( 892 and 894 $\mathrm{pm})$.

The shortest contacts between the enclosed acetonitrile $\left(\mathrm{H}_{3} \mathrm{CCN}\right.$ and $\mathrm{H}_{3} \mathrm{C}^{\prime} \mathrm{C}^{\prime} \mathrm{N}^{\prime}$ respectively) and two benzene rings

\pm Crystal data: $\mathrm{C}_{56} \mathrm{H}_{38} \mathrm{O}_{6}, M=3268.7$, monoclinic, $P 2_{1} / c, a=$ $11.546(7), b=19.135(8), c=23.492(18) \AA, \beta=102.32(3)^{\circ}, V=$ $5071.2 \AA^{3}, Z=4, D_{\mathrm{c}}=1.0703 \mathrm{~g} \mathrm{~cm}^{-3}, \lambda(\mathrm{Mo}-\mathrm{K} \alpha)=0.71069 \AA, F(000)$ $=1710, T=295 \mathrm{~K}$. In the range $2^{\circ}<2 \theta<50^{\circ}$ a total of 18361 intensity data were measured on an Enraf-Nonius CAD4 diffractometer (graphite-monochromatized Mo-K $\alpha$ radiation) using the $\omega-\theta$ scan mode. Data reduction $\left(R_{\mathrm{int}}=0.0196\right)$ yielded 4667 symmetryindependent data with $F_{\mathrm{o}}>3 \sigma\left(F_{\mathrm{o}}\right)$. The structure was determined by direct methods and refined by block-matrix least-squares methods ${ }^{5}$ minimizing the quantity $\Sigma w^{\frac{1}{2}} \Delta\left[\Delta=\left\|F_{\mathrm{o}}|-| F_{\mathrm{c}}\right\|, w=3.5 /\left(\sigma^{2}\left(F_{\mathrm{o}}\right)+\right.\right.$ $\left.4.5 \times 10^{-4} F_{\mathrm{o}}^{2}\right]$. Anisotropic thermal parameters were refined for all non-H atoms. Hydrogen atoms were placed in calculated positions. Benzene rings were treated as rigid groups. The disordered $\mathrm{MeCN}$ solvent molecules were refined isotropically as rigid groups on two split positions (each with a refined occupancy factory of about 0.5 ). Final $R=0.0977$ and $R_{\mathrm{w}}=0.0956$; residual electron density $0.28 \mathrm{e}$ $\AA^{-3}$. Atomic coordinates, bond lengths and angles, and thermal parameters have been deposited at the Cambridge Crystallographic Data Centre. See Notice to Authors, Issue No. 1.

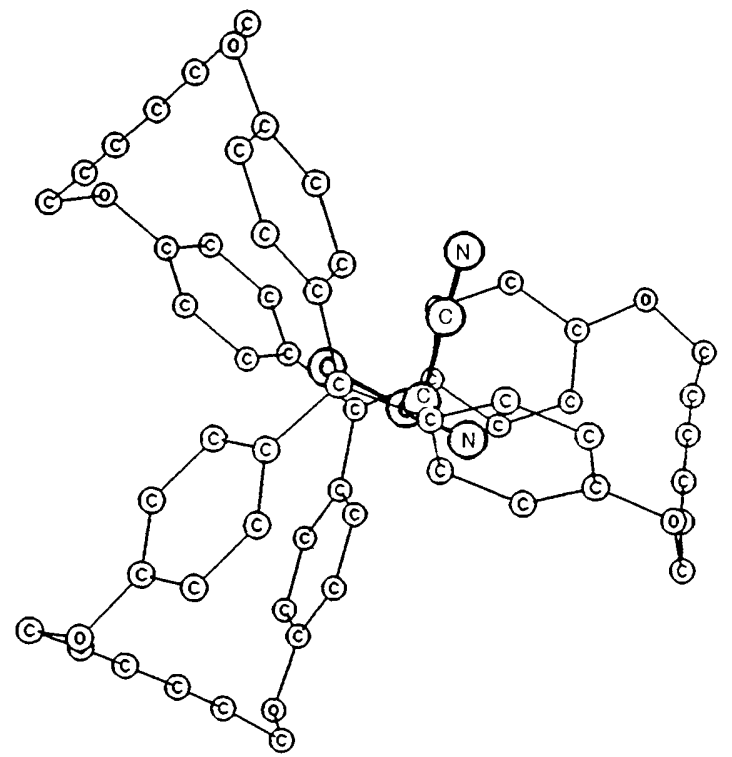

Fig. 2 View of complex $4 \cdot \mathrm{MeCN}$ along its pseudo- $C_{3}$ axis. Hydrogen atoms are omitted for clarity.

are found with rings $A$ and $B$ (mean value $\approx 400 \mathrm{pm}$ ) and with rings $\mathrm{A}^{\prime}$ and $\mathrm{B}^{\prime}$ (mean value $\approx 390 \mathrm{pm}$ ) respectively. The structural environment of the enclosed acetonitrile $\left(\mathrm{H}_{3} \mathrm{CCN}\right)$ relative to the host benzene rings $\mathrm{A}$ and $\mathrm{B}$ is similar to that of the disordered counterpart $\left(\mathrm{H}_{3} \mathrm{C}^{\prime} \mathrm{C}^{\prime} \mathrm{N}^{\prime}\right)$ relative to benzene rings $A^{\prime}$ and $B^{\prime}$. Ring $A$ is nearly perpendicular to an imaginary line between rings $\mathrm{A}$ and $\mathrm{B}$ (cf. Fig. 1$)$. In contrast, ring $\mathrm{B}$ is twisted relative to $\mathrm{A}$. For the enclosed acetonitrile $\left(\mathrm{H}_{3} \mathrm{CCN}\right)$ this results in an interaction of ring $A$ with the nitrile function (distance $\approx 400 \mathrm{pm}$ ) in which the $\pi$-orbitals of the phenoxy ring $A$ and the nitrile function would overlap (similar to face-to-face interaction). ${ }^{6}$ Ring $\mathrm{B}$ shows a different kind of interaction: two $\mathrm{C}-\mathrm{H}$ groups of ring $\mathrm{B}$ project towards the nitrile function including a 'crosswise' placement of the $\pi$-orbitals of ring B and the nitrile group. This interaction is reminiscent of the well known attractive edge-to-face interaction between two aromatic systems. ${ }^{6}$

The first type of interaction seems to be consistent with the spectral data; the shift of the nitrile band from 2254 to 2219 $\mathrm{cm}^{-1}$ might be interpreted as resulting from a partial elongation of the $\mathrm{C} \equiv \mathrm{N}$ bond as a consequence of $\pi$-stacking and charge-transfer interactions. 
A further indication of an attractive interaction between host $\mathbf{4}$ and the acetonitrile guest is the fact that a related host described by Breslow 4 encloses benzene in the cavity of the molecule as well as in the intermolecular crystal cavities, whilst the acetonitrile as a $\pi$-acceptor in our host 4 selects exclusively the host molecules and occupies no intermolecular cavities.

In accord with these interpretations, other $\pi$-acceptor guest molecules also form complexes with the host 4: for phenylacetonitrile and $p$-fluorobenzyl chloride as acceptors, we also identified complexes by comparing the IR spectra of free and complexed guest (in the crystal). The structures of these complexes have yet to be studied. On the other hand, possible guests such as benzonitrile, diphenylacetonitrile or trichloroacetonitrile seem not to form complexes of this type, possibly for steric reasons. Other $\pi$-donor systems related to 4 will be examined by us for possible inclusions of acceptor guests. This behaviour might be useful for sensor applications.

We thank the Fonds der Chemischen Industrie for support and Dr J. Arlt for the IR spectra.

Received, 9th November 1990; Com. 0/05051B

\section{References}

1 C. L. Liotta, H. P. Harris and F. L. Cook, J. Org. Chem., 1974, 39 2445; I. Goldberg, Acta Crystallogr., Sect. B., 1975, 31, 754; T. C. W. Mak and K.-S. Lee, Acta Crystallogr., Sect. B, 1978, 34, 3631 I. Tanaka, I. Tajima, Y. Hayakawa, M. Okada, M. Bitoh, T.
Ashida and H. Sumitomo, J. Am. Chem. Soc., 1980, 102, 7873; I. Sakuragi, I. Tanaka, T. Ashida, I. Tajima, M. Okada and H. Sumitomo, J. Am. Chem. Soc., 1982, 104, 6035; T.-L. Chan and T. C. W. Mak, J. Chem. Soc., Perkin Trans. 2, 1983, 777; C. J. Gilmore, D. D. MacNicol, A. Murphy and M. A. Russell, Tetrahedron Lett., 1983, 24, 3269; R. D. Rogers, L. K. Kurihara and P. D. Richards, J. Chem. Soc., Chem. Commun., 1987, 604; E. Weber, S. Franken, J. Ahrendt and H. Puff, J. Org. Chem., 1987, 52, 5291; R. D. Rogers, P. D. Richards and E. J. Voss, J. Incl. Phenom., 1988, 6, 65; R. L. Garrell, J. C. Smyth, F. R. Fronczek and R. D. Gandour, J. Incl. Phenom., 1988, 6, 73; R. D. Rogers, J. Incl. Phenom., 1988, 6, 629; P. D. J. Grootenhuis and P. A. Kollman, J. Am. Chem. Soc., 1989, 111, 4046; K. Panneerselvam, K. K. Chacko, E. Weber and H.-J. Köhler, J. Incl. Phenom., 1990, 9, 337.

2 R. R. Otter and R. L. Shriner, J. Am. Chem. Soc., 1951, 73, 887; H. H. Burton and G. W. H. Cheeseman, J. Chem. Soc., 1953, 832; N. C. Deno, J. J. Jaruzelski and A. Schriesheim, J. Am. Chem. Soc., 1955, 77, 3044.

3 G. I. Feutrill and R. N. Mirrington, Tetrahedron Lett., 1970, 1327: Aust. J. Chem., 1972, 25, 1719.

4 D. O'Krongly, S. R. Denmeade, M. Y. Chiang and R. Breslow, J. Am. Chem. Soc., 1985, 107, 5544.

5 G. M. Sheldrick, SHELX-76, program for crystal structure determination, Cambridge, 1976.

6 For general discussion of edge-to-face, face-to-face and edge-on interactions see: G. Karlström, P. Linse, A. Wallqvist and B. Jönsson, J. Am. Chem. Soc., 1983, 105, 3777; R. O. Gould, A. M. Gray, P. Taylor and M. D. Walkinshaw, J. Am. Chem. Soc., 1985, 107, 5921; S. K. Burley and G. A. Petsko, Science, 1985, 229 23; S. K. Burley and G. A. Petsko, J. Am. Chem. Soc., 1986, 108, 7995 C. A. Hunter and J. K. M. Sanders, J. Am. Chem. Soc., 1990, 112, 5525; herringbone structures are discussed in: G. R. Desiraju and A. Gavezzotti, J. Chem. Soc., Chem. Commun., 1989, 621. 